\title{
Comparison of the Achilles Express Ultrasonometer with Central Dual-Energy X-Ray Absorptiometry
}

\author{
Darren W Grabe, Jennifer Cerulli, Jeffrey S Stroup, and Michael P Kane
}

\begin{abstract}
BACKGROUND: Quantitative ultrasound (QUS) devices provide portable, easy-to-operate, low-cost options for point-of-care screening of bone mineral density (BMD). Community pharmacists should be aware of the precision, sensitivity, and specificity of these devices prior to their purchase.

OBJECTIVE: To determine the precision, sensitivity, and specificity of the Achilles Express ultrasonometer compared with central dual-energy X-ray absorptiometry (cDXA) as well as its utility as a bone density screening device in the community pharmacy setting.
\end{abstract}

METHODS: A prospective study in a community pharmacy and outpatient ambulatory clinic was conducted with 2 groups of white women. Group 1 participants were 25-35 years of age (young, healthy), and those in Group 2 were 45 years of age or older (postmenopausal). BMD assessments of the spine and the nondominant wrist and hip were performed using cDXA. Assessments of the heel were performed using the Achilles Express, a QUS device. The main outcome measures were correlation of $t$-scores between cDXA and QUS measurements using the Pearson correlation test.

RESULTS: Twenty-two ( $30 \pm 4$ years of age) and 31 ( $55 \pm 17$ years of age) women were enrolled into Groups 1 and 2 , respectively. Significant correlations between QUS and hip and spine cDXA $t$ scores were found in both groups. Correlation coefficients for QUS versus hip cDXA were $0.51(95 \% \mathrm{Cl} 0.11$ to 0.77$)$ and $0.70(95 \% \mathrm{Cl} 0.46$ to 0.85$)$ in Groups 1 and 2, respectively. Correlation coefficients for the QUS versus spine cDXA were $0.64(95 \% \mathrm{Cl} 0.31$ to 0.84$)$ and 0.60 (95\% $\mathrm{Cl} 0.31$ to 0.79$)$ in Groups 1 and 2 , respectively. The QUS device has a sensitivity level of $88 \%$ and specificity of $71 \%$ to detect a hip cDXA $t$ score of less than -1 .

CONCLUSIONS: The Achilles Express ultrasonometer is a reasonable screening tool to detect low BMD in postmenopausal women. KEY WORDS: bone mineral density, DXA, osteoporosis, quantitative ultrasound, screening tool.

Ann Pharmacother 2006;40:830-5.

Published Online, 2 May 2006, www.theannals.com, DOI 10.1345/aph.1G549

$\mathrm{O}$ steoporosis leads to significant morbidity and mortality, including 250000 hip fractures in women annually in the US. ${ }^{1}$ A minority (one-third) of these osteoporotic women are diagnosed and even fewer (14\%) receive treatment. The diagnosis of osteoporosis involves physical assessment, identification of risk factors, and bone mineral density (BMD) testing. According to the World Health Organization, BMD is best expressed as a $t$-score, the number of standard deviations (SD) above or below the average bone density of young, healthy adults. ${ }^{2}$

Author information provided at the end of the text.
The gold standard for BMD assessment is central dualenergy X-ray absorptiometry (cDXA). ${ }^{1}$ Due to the high cost of and limited access to cDXA testing, alternative methods are available for use in the ambulatory care setting for point-of-care (POC) screening. These devices, including peripheral DXA and quantitative ultrasound (QUS), provide portable, easy-to-operate, low-cost screening options.-5 In previous studies, $t$-scores obtained from QUS devices have been shown to correlate significantly with cDXA. ${ }^{6-10}$ However, these correlations are modest and their discordance from the cDXA $t$-scores may be due to several factors, including the fact that measurements are obtained at different sites with varying rates of age-related 
bone loss, differences in the manufacturer's published normal reference populations, and the possibility that the devices do not measure the same bone properties. ${ }^{5}$

Regardless of these differences, heel (os calcis) QUS measurements have been shown to predict osteoporosis-related fractures in women. ${ }^{11-15}$ In one investigation, heel QUS predicted hip fracture in women over 75 years of age as well as hip cDXA did. ${ }^{11}$ Data supporting the use of QUS to predict fracture risk in younger women are limited. However, low QUS values in women 45-75 years of age have predicted wrist and other osteoporosis-related fractures with a level of accuracy similar to that of cDXA. ${ }^{12}$ In a large study involving more than 200000 postmenopausal women over the age of 50 years, a variety of peripheral BMD devices predicted overall fracture risk. ${ }^{13}$

Community pharmacies provide a convenient setting for POC BMD testing. Studies have documented the impact of community pharmacy screening programs using either peripheral DXA or QUS POC devices. ${ }^{16-19}$ Peripheral DXA, which requires radiation to deliver results, has created safety concerns, causing some states to impose regulatory restrictions regarding its use in community pharmacies. The Food and Drug Administration has approved QUS devices that provide community pharmacies with an alternative method to screen for low BMD. Community pharmacists should be aware of the precision, sensitivity, and specificity of various QUS devices prior to purchase; differences in such parameters can affect the validity of obtained results and subsequent pharmacist recommendations for further patient follow-up. Of particular importance is the fact that the screening results do not provide a high rate of false negatives, a result that would give a patient the impression that she is at low fracture risk when, in fact, cDXA would reveal that she is at high risk for fracture.

The Achilles + (Lunar Corp., Madison, WI) QUS device, which has been shown to correlate with cDXA of the hip $(r=0.80$ femoral neck, $p<0.001)$ and spine $(r=0.67$ spine, $\mathrm{p}<0.001)$, requires a patient's foot to be submerged in a warm water bath. ${ }^{6}$ To decrease testing time and increase operator convenience, the Achilles + was replaced by the Achilles Express, which does not use a water bath. The Achilles Express determines a stiffness index (SI) that is expressed as a $t$-score to indicate the risk of osteoporotic fracture in postmenopausal women. The SI is comparable to BMD as measured by cDXA. ${ }^{20}$ Physicians can use the $t$ score in conjunction with other risk factors to assist in the diagnosis of osteoporosis in the same way that cDXA $t$ scores can be used. ${ }^{20,21}$ Although the manufacturer reports a strong correlation between the Achilles Express and the Achilles $+(\mathrm{r}=0.94)$, there is only one published abstract that directly compares the Achilles Express with cDXA.22 Data from 8 patients with chronic kidney disease, who were on prolonged corticosteroid therapy, identified a sig- nificant correlation between the dominant and nondominant heel Achilles Express QUS results and hip cDXA ( $\mathrm{r}=$ 0.84 and $\mathrm{r}=0.84$, respectively; $\mathrm{p}<0.01$ ). However, no correlation existed between the dominant or nondominant heel results of the Achilles Express QUS and spine cDXA $(r=0.61$ and $r=0.47$, respectively; $p>0.1)$.

The Achilles Express is commercially available for use in community pharmacies as a bone density screening tool. The objective of this study was to compare the precision, sensitivity, and specificity of the Achilles Express device with cDXA and determine its utility as a screening tool for low BMD. This investigation included 2 groups of subjects to determine the sensitivity and specificity of the device in women at minimal risk for low BMD (young, healthy) and women at higher risk (postmenopausal).

\section{Methods}

This study was approved by the institutional review board and the Radioisotope and Radiation Safety Committee of Albany Medical College. Using a board-approved flyer, subjects were recruited from the Albany College of Pharmacy faculty and staff and from an investigator's clinical practice site. Healthy women between the ages of 25 and 35 years were considered eligible for inclusion in Group 1 if they were not pregnant and not taking any drugs known to affect BMD (eg, bisphosphonates, calcitonin, parathyroid hormone, corticosteroids). Women 45 years of age or older were considered eligible for inclusion in Group 2 if they were postmenopausal (defined as absence of menses for $>1 \mathrm{y}$ or surgical menopause). There were no drug exclusion criteria in Group 2. The criteria for subject recruitment and target enrollment numbers ( 25 in Group 1, 50 in Group 2) were chosen to replicate previously published research involving QUS devices. ${ }^{6}$ White women were included in this study because the QUS device utilized population data from white women to report $t$ - and $z$-scores. ${ }^{20}$

Recruited subjects were referred to a private endocrinology practice to schedule appointments for cDXA and QUS BMD assessments. After informed consent was obtained, demographic information and history (height, weight, dominant hand, medications, medical history) were collected. Urine pregnancy tests were conducted in Group 1 subjects prior to the cDXA test. One certified DXA technician performed all BMD assessments of the nondominant wrist and hip (neck, trochanter) and the spine (L1-L4) using the Delphia SL QDR series fan beam device (Hologic Inc., Bedford, MA) with all $t$-scores recorded. Osteopenia ( $t$-score less than -1 and greater than -2.5 ) and osteoporosis ( $t$-score -2.5 or less) were defined according to diagnostic guidelines of the World Health Organization. ${ }^{2}$

Peripheral BMD measurements were assessed 3 times in each heel using the Achilles Express QUS device. Assessments were conducted by a single investigator to avoid introducing interobserver bias. The Achilles Express QUS device combines broadband ultrasound attenuation and speed of sound to reduce random measurement errors and provide greater precision in estimating fracture risk. Tissue attenuation was determined by the change in ultrasound intensity measured between 2 transducers. ${ }^{5}$ The Achilles Express combines broadband ultrasound attenuation and speed of sound into the SI, which is then compared with age-matched controls to determine a $t$-score equivalent. ${ }^{20}$ The $t$-score equivalents are reported in this study.

Statistical analyses were performed with the Minitab statistical package, release 14 (Minitab Inc., State College, PA). Descriptive statistics are used to describe demographic data. To determine the positioning precision (repeat measurements on the same day with repositioning) of this 
device in our hands, the coefficient of variation of the SI using the 3 QUS measurements obtained from both heels was calculated. Correlation coefficients (r) between QUS and cDXA measurements of the spine and hip were determined by the Pearson correlation test, using the median of the 3 QUS readings obtained in the nondominant heel. Regression analysis was performed using the median of the 3 QUS readings on each of the comparisons (QUS-dominant vs DXA-hip, QUS-dominant vs DXA-spine, QUS-nondominant vs DXA-hip, QUS-nondominant vs DXA-spine) to determine the $r^{2}$, which indicates the amount of variance in one variable attributed to changes in a predictor variable. ${ }^{23}$ To determine the utility of QUS for screening in the community pharmacy setting, the sensitivity, specificity, positive predictive value (PPV), and negative predictive value (NPV) for the QUS device to detect osteopenia in comparison with cDXA were determined. Sensitivity and specificity were defined as the ability of the QUS device to correctly identify patients with or without osteopenia on CDXA at the spine and hip. The PPV and NPV were defined as the percent of patients having been correctly identified with or without osteopenia by QUS based on cDXA. These values assess the reliability of a positive or negative QUS test. A positive QUS test or CDXA was defined as a $t$-score of -1 or less, while a negative QUS test or CDXA indicated the absence of disease with a $t$ score greater than -1 . For purposes of assessing risk of fracture and calculating sensitivity, specificity, PPV, and NPV, the results for the nondominant heel were used. The dominant heel was not used since it is assumed to have higher BMD values due to increased physical use compared with the nondominant heel. ${ }^{3}$

\section{Results}

Fifty-four subjects were recruited over 7 months; however, one subject in Group 1 was excluded following a positive urine test for pregnancy. Thus, 53 subjects completed the study, with 22 subjects in Group 1 and 31 in Group 2. One subject in each group did not complete a cDXA of the spine and wrist due to contraindications. Target enrollment of 25 and 50 subjects in Groups 1 and 2, respectively, was not achieved due to logistical issues limiting enrollment during the time in which one investigator could serve as the QUS operator. These issues included conflicts in scheduling and the end of recruitment upon completion of the QUS operator's residency program. The positioning precision of the device in the hands of the single operator was $5.6 \%$, which is consistent with a previous study investigating QUS devices (range 1.6-7.0\%). ${ }^{6}$

Demographic data for the study participants are presented in Table 1. In addition to the expected differences in the mean age, there were significant differences in body mass index, past smoking history, and use of thyroid and antiresorptive drug therapies. Correlation coefficients between QUS and cDXA measurements are presented in Table 2. Although weight has been shown to be an independent predictor of BMD as measured by QUS, post hoc analysis showed no correlation. Figure 1 illustrates the correlation of QUS of the nondominant heel with spine (1a) and hip (1b) cDXA in each group of women. The figure also demonstrates the frequency of false positive and negative results as they relate to osteopenia, defined with a line of identity at a $t$-score of -1 . Mean $t$-scores demonstrated for all cDXA scans (hip, spine, wrist) as well as QUS measurements (dominant, nondominant foot) in Group 1 were significantly different $(\mathrm{p}<0.05)$ from those in Group 2. The mean \pm SD cDXA $t$-scores in Group 1 were $0.1 \pm 0.8$,

\begin{tabular}{|lcc|}
\hline \multicolumn{2}{|c|}{ Table 1. Demographic Data of Study Participants } \\
\hline \multicolumn{1}{|c|}{ Characteristic } & $\begin{array}{c}\text { Group 1 } \\
\text { Young, Healthy } \\
(\mathbf{n}=\mathbf{2 2})^{\mathbf{a}}\end{array}$ & $\begin{array}{c}\text { Group 2 } \\
\text { Postmenopausal } \\
(\mathbf{n}=\mathbf{3 1})^{\mathbf{a}}\end{array}$ \\
\hline Age, y & $30 \pm 4$ & $55 \pm 17^{\mathbf{b}}$ \\
Height, in. & $64 \pm 2$ & $63 \pm 2.7$ \\
Weight, kg & $64.41 \pm 13.61$ & $69.85 \pm 9.98$ \\
Body mass index, kg/m ${ }^{2}$ & $24 \pm 5$ & $27 \pm 4^{\mathbf{b}}$ \\
Postmenopause, y & & $10 \pm 9$ \\
Current smoker & $1(5)$ & $1(3)$ \\
Past smoker & $4(18)$ & $16(52)^{\mathbf{b}}$ \\
Caffeine $>5$ cups/day & $3(14)$ & $2(6)$ \\
Family history, fracture & $8(36)$ & $10(32)$ \\
Adult fracture & $2(9)$ & $9(29)$ \\
Medication history & & \\
steroid (oral or inhaled) & 0 & $2(6)$ \\
diuretic & 0 & $2(6)$ \\
anticonvulsant & 0 & $1(3)$ \\
immunosuppressant & 0 & $1(3)$ \\
thyroid & 0 & $7(23)^{\mathbf{b}}$ \\
antiresorptive therapy & 0 & $5(16)^{\mathbf{b}}$ \\
hormone replacement/OC & $3(14)$ & $10(32)$ \\
natural estrogens & 0 & $1(3)$ \\
multivitamin & $14(64)$ & $15(48)$ \\
calcium & $9(41)$ & \\
\hline OC = oral contraceptive. & & \\
aResults are presented as mean \pm SD or $\mathbf{n}(\%)$. & \\
bp 0.05. & & \\
\hline
\end{tabular}

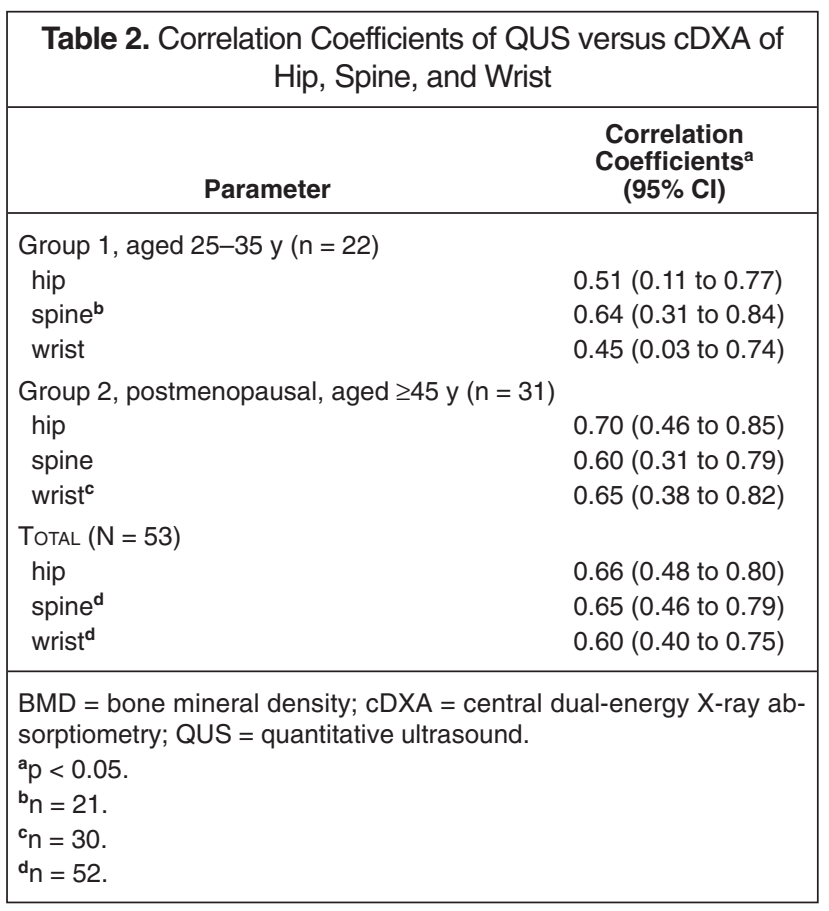


$-0.1 \pm 0.8(\mathrm{n}=21)$, and $0.6 \pm 0.9$ for the hip, spine, and wrist, respectively; in Group 2, they were $-0.6 \pm 1.2,-1.0$ \pm 1.3 , and $0.0 \pm 1.5(\mathrm{n}=30)$ for the hip, spine, and wrist, respectively. The mean \pm SD QUS $t$-scores in Group 1 were $-0.2 \pm 1.2$ and $-0.0 \pm 1.2$ for the nondominant and dominant ankles, respectively, and in Group 2 were $-1.1 \pm$ 1.2 and $-1.0 \pm 1.3$ for the nondominant and dominant ankles, respectively. Sensitivity, specificity, PPV, and NPV data are presented in Table 3.

\section{Discussion}

Similar to previous studies comparing other QUS devices, our results show modest but significant correlations of QUS with cDXA ( $r=0.65$ spine, $r=0.66$ hip $){ }^{6-10}$ The Achilles + first-generation device demonstrated significant correlations with cDXA of the spine, femoral neck, and trochanter $\left(\mathrm{r}=0.678,0.8,0.7\right.$, respectively). ${ }^{6}$ There are numerous reasons for the lack of correlation (or discordance) found when comparing BMD results from QUS and cDXA devices. $^{5}$
Due to this discordance, it is important for pharmacists conducting BMD screenings to identify the sensitivity and specificity of the device to detect osteopenia in the population being screened. The results in Table 3 indicate that QUS has variable rates of sensitivity and specificity in the 2 populations studied. The Achilles Express identified postmenopausal (Group 2) patients with osteopenia of the hip and spine with a $92 \%$ and $79 \%$ sensitivity, respectively, and provided a low number of false negative results (patient having normal heel QUS but osteopenia on cDXA measurements). Otherwise stated, BMD screening in postmenopausal women with the Achilles Express would miss approximately 1 in 10 women with osteopenia at the hip and 2 in 10 women with osteopenia at the spine. The specificity of $63 \%$ and $59 \%$ for the hip and spine comparisons, respectively, indicates that use of the Achilles Express may lead to a 30-40\% incidence of false positive results (patients categorized with osteopenia by QUS when cDXA does not indicate osteopenia). This could result in unnecessary follow-up cDXA testing. However, given the high NPV (92\% at hip), pharmacists can be confident that a
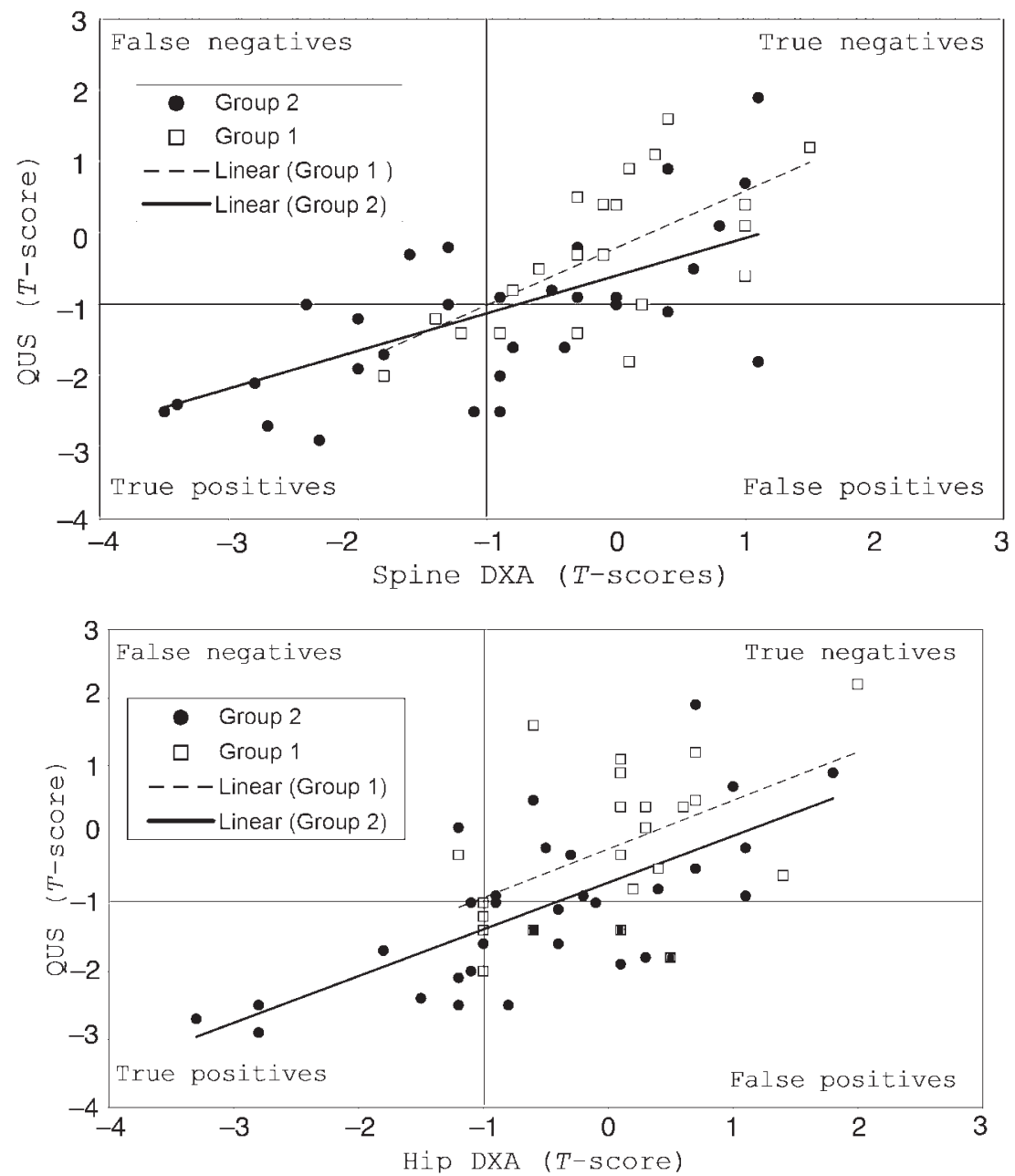

Figure 1. Illustration of the correlation between the quantitative ultrasound of the nondominant heel versus the central DXA of the spine and of the hip in all women. DXA = dual-energy X-ray absorptiometry. 
negative QUS result for osteopenia in this population is truly negative for disease at the hip, which incurs considerable morbidity and mortality.

While the data support the role of QUS in predicting fracture risk in females over the age of 45 years, ${ }^{11-14}$ concerns over its discordance with cDXA have led to recommendations regarding its use for screening this population. ${ }^{5}$ The recommendations include follow-up cDXA scans for patients with QUS-determined $t$-scores below -1 and for patients with QUS $t$-scores between +1 and -1 if significant risk factors are present. An example of a screening tool to evaluate fracture risk is the Simple Calculated Osteoporosis Risk Estimation, which can be completed easily in a community pharmacy setting. ${ }^{24,25}$ This tool has been studied in combination with QUS screening and has been shown to improve sensitivity at the cost of lowering specificity. ${ }^{10}$

In the young, healthy population (Group 1), the sensitivity of the Achilles Express to detect osteopenia was 100\% in the spine and $80 \%$ in the hip. While $100 \%$ sensitivity and a high NPV (negative result truly negative) are encouraging, caution is warranted in interpreting these results, as few of these study participants had documented osteopenia. When the prevalence of disease is low, PPV will decrease and NPV will rise. ${ }^{27}$ The potential exists for a high rate of false negatives for osteopenia using QUS in a younger population because BMD measured at peripheral sites (heel, finger) may be greater than BMD measured at central sites (lumbar spine) in this population. ${ }^{5,28}$ In other words, a negative result with peripheral BMD in younger patients, which involves measurement of primarily cortical bone, does not rule out the existence of bone loss at central sites, which are primarily composed of trabecular bone.

\begin{tabular}{|c|c|c|c|c|}
\hline \multicolumn{5}{|c|}{$\begin{array}{c}\text { Table 3. Sensitivity and Specificity of QUS versus } \\
\text { cDXA in BMD Testing }\end{array}$} \\
\hline Parameter & $\begin{array}{l}\text { Sensitivity, } \\
\%(95 \% \mathrm{Cl}) \\
80 \text { (30 to } 99)\end{array}$ & $\begin{array}{c}\text { Specificity, } \\
\%(95 \% \text { Cl) } \\
77 \text { (50 to } 92)\end{array}$ & $\begin{array}{c}\text { PPV } \\
(\%)\end{array}$ & $\begin{array}{c}\text { NPV } \\
(\%)\end{array}$ \\
\hline \multicolumn{5}{|c|}{$\begin{array}{l}\text { Group 1, aged 25- } \\
35 \text { y }(n=22)\end{array}$} \\
\hline hip & 80 (30 to 99$)$ & 77 (50 to 92) & 50 & 93 \\
\hline spine $^{a}$ & $100(31$ to 100$)$ & 77 (50 to 92$)$ & 43 & 100 \\
\hline \multicolumn{5}{|c|}{$\begin{array}{l}\text { Group 2, postmen- } \\
\text { opausal, aged } \\
\geq 45 \text { y }(n=31)\end{array}$} \\
\hline hip & $92(60$ to 100$)$ & 63 (39 to 83 ) & 61 & 92 \\
\hline spine & 79 (49 to 94$)$ & 59 (34 to 81$)$ & 61 & 77 \\
\hline \multicolumn{5}{|l|}{ TOTAL $(\mathrm{N}=53)$} \\
\hline hip & 88 (60 to 98$)$ & 71 (54 to 85$)$ & 58 & 93 \\
\hline spine & 82 (56 to 95$)$ & 69 (51 to 83$)$ & 56 & 89 \\
\hline \multicolumn{5}{|c|}{$\begin{array}{l}\text { BMD = bone mineral density; } c D X A=\text { central dual-energy } X \text {-ray ab- } \\
\text { sorptiometry; } N P V=\text { negative predictive value; } P P V=\text { positive predic- } \\
\text { tive value; } Q U S=\text { quantitative ultrasound. } \\
{ }^{a_{n}=21} .\end{array}$} \\
\hline
\end{tabular}

Limitations of this study include a low rate of those with $t$-scores indicating osteopenia and the relatively young age of participants. Thus, the correlation of the QUS device with cDXA in an older female population or those with defined osteoporosis is unknown and deserves further study. Our study had a relatively small sample size, which limited our ability to identify substantial numbers of patients positive for the disease. This can impact the PPV and NPV results obtained. ${ }^{27}$

\section{Conclusions}

Pharmacists selecting a peripheral BMD screening device should familiarize themselves with the technology available and the advantages and disadvantages of those options..$^{3-5}$ The Achilles Express ultrasonometer is a reasonable screening tool for identifying low BMD in postmenopausal women. However, the low rate of disease in women under 35 years of age warrants caution regarding the use of this device as a screening tool to identify low BMD in a young, premenopausal population.

Darren W Grabe PharmD, Associate Professor, Albany College of Pharmacy; Adjunct Assistant Professor, Albany Medical College, Albany, NY

Jennifer Cerulli PharmD BCPS, Associate Professor, Albany College of Pharmacy

Jeffrey S Stroup PharmD BCPS, at time of writing, Resident, Albany College of Pharmacy; now, Clinical Assistant Professor, College of Pharmacy, University of Oklahoma, Norman, OK

Michael P Kane PharmD FCCP BCPS, Associate Professor, Albany College of Pharmacy; Clinical Pharmacy Specialist, The Endocrine Group, LLP, Albany

Reprints: Dr. Grabe, Department of Pharmacy Practice, Albany College of Pharmacy, 106 New Scotland Ave., Albany, NY 122083425, fax 518/694-9018, grabed@ acp.edu

Presented at the American College of Clinical Pharmacy 2005 Spring Practice and Research Forum, Myrtle Beach, SC, April 10-13, 2005. This study was funded by an Albany College of Pharmacy intramural grant.

We acknowledge Pamela L Sherman LRT CDT for conducting all cDXA scans in this study.

\section{References}

1. Hodgson SF, Watts NB, Bilezikian JP, et al. American Association of Clinical Endocrinologists medical guidelines for clinical practice for the prevention and treatment of postmenopausal osteoporosis: 2001 edition, with selected updates for 2003. Endocr Pract 2003;9:544-64.

2. World Health Organization. Assessment of fracture risk and application to screening for postmenopausal osteoporosis. Geneva, Switzerland: World Health Organization, 1994.

3. DeHart RM, Gonzalez EH. Osteoporosis: point-of-care testing. Ann Pharmacother 2004;38:473-81. Epub 1 Mar 2004. DOI 10.1345/aph.1D229

4. Rosenthal WM. Implementing bone mineral density testing in the community pharmacy. J Am Pharm Assoc 2000;40:737-45.

5. National Osteoporosis Foundation. Osteoporosis clinical updates. Clinical uses of ultrasound. Winter 2002;3. www.nof.org/cmeexam/QUSissuePDF. pdf (accessed 2004 Nov 18).

6. Greenspan SL, Bouxsein ML, Melton ME, et al. Precision and discriminatory ability of calcaneal bone assessment technologies. J Bone Miner Res 1997;12:1303-13. 
7. Faulkner KG, McClung MR, Coleman LJ, Kingston-Sandahl E. Quantitative ultrasound of the heel: correlation with densitometric measurements at different skeletal sites. Osteoporos Int 1994;4:42-7.

8. Gonnelli S, Cepollaro C, Agnusdei D, Palmieri R, Rossi S, Gennari C. Diagnostic value of ultrasound analysis and bone densitometry as predictors of vertebral deformity in postmenopausal women. Osteoporos Int 1995;5:413-8.

9. Cepollaro C, Gonnelli S, Pondrelli C, et al. The combined use of ultrasound and densitometry in the prediction of vertebral fracture. Br J Radiol 1997;70;691-6.

10. Ayers M, Prince M, Ahmadi S, Baran DT. Reconciling quantitative ultrasound of the calcaneus with X-ray-based measurements of the central skeleton. J Bone Miner Res 2000;15:1850-5.

11. Hans D, Dargent-Molina P, Schott AM, et al. Ultrasonographic heel measurements to predict hip fracture in elderly women: the EPIDOS prospective study. Lancet 1996;348:511-4.

12. Thompson PW, Taylor J, Oliver R, Fisher A. Quantitative ultrasound (QUS) of the heel predicts wrist and osteoporosis-related fractures in women age 45-75 years. J Clin Densitom 1998;1:219-25.

13. Siris ES, Miller PD, Barrett-Connor E, et al. Identification and fracture outcomes of undiagnosed low bone mineral density in postmenopausal women. Results from the National Osteoporosis Risk Assessment. JAMA 2001;286:2815-22.

14. Bauer DC, Gluer CC, Cauley JA, et al. Broadband ultrasound attenuation predicts fractures strongly and independently of densitometry in older women. A prospective study. Study of Osteoporotic Fractures Research Group. Arch Intern Med 1997;157:629-34.

15. National Osteoporosis Foundation. Physician's guide to prevention and treatment of osteoporosis. www.nof.org/physguide/diagnosis.htm (accessed 2004 Nov 22).

16. Goode JV, Swiger K, Bluml BM. Regional osteoporosis screening, referral, and monitoring program in community pharmacies: findings from Project ImPACT: Osteoporosis. J Am Pharm Assoc 2004;44:152-60.

17. Cerulli J, Zeolla MM. Impact and feasibility of a community pharmacy bone mineral density screening and education program. J Am Pharm Assoc 2004;44:161-7.

18. Elliot ME, Meek PD, Kanous NL, et al. Osteoporosis screening by community pharmacists: use of National Osteoporosis Foundation resources. J Am Pharm Assoc 2002;42:101-10.

19. Elliott ME, Meek PD, Kanous NL, Schill GR, Weinswig PA, Bohlman JP. Pharmacy-based bone mass measurement to assess osteoporosis risk. Ann Pharmacother 2002;36:571-7. DOI 10.1345/aph.1A299

20. Product information. Achilles Express Ultrasonometer. Waukesha, WI: GE Healthcare Technologies, January 2001.

21. Huopio J, Kroger H, Honkanen R, Jurvelin J, Saarikoski S, Alhava E. Calcaneal ultrasound predicts early postmenopausal fractures as well as axial BMD. A prospective study of 422 women. Osteoporos Int 2004 15:190-5. Epub 16 Jan 2004.

22. Grabe DW, Chan M, Eisele G. Comparison of ankle quantitative ultrasound and dual-energy X-ray absorptiometry (DEXA) scans in patients with chronic kidney disease and prolonged corticosteroid therapy (abstract). Presented at: National Kidney Foundation Clinical Nephrology Meetings, Chicago, April 17-21, 2002.

23. Gehlbach SH. Interpreting the medical literature. 3rd ed. New York: McGraw-Hill, 1993.

24. Miller PD, Njeh CF, Jankowski LG, Lenchik L. What are the standards by which bone mass measurement at peripheral sites should be used in the diagnosis of osteoporosis? J Clin Densitom 2002;5(suppl):S39-45.

25. Lydick E, Cook K, Turpin J, Melton M, Stine R, Byrnes C. Development and validation of a simple questionnaire to facilitate identification of women likely to have low bone density. Am J Manag Care 1998;4:37-48.

26. Cadarette SM, Jaglal SB, Murray TM, McIsaac WJ, Joseph L, Brown JP. Evaluation of decision rules for referring women for bone density by dual-energy X-ray absorptiometry. JAMA 2001;286:57-63.

27. Loong T-W. Understanding sensitivity and specificity with the right side of the brain. BMJ 2003;327:716-9.

\section{EXTRACTO}

TRASFONDO: Los dispositivos cuantitativos de ultrasonido (CUS) proveen una opción fácil de operar, económica, y posible de portear para la detección de la densidad mineral ósea (DMO) en el lugar de cuidado
(LDC). Los farmacéuticos de la comunidad deben conocer la precisión, la sensibilidad, y la especificidad de los dispositivos CUS antes de comprarlos.

OBJETIVo: Determinar la precisión, la sensibilidad, y la especificidad del ultrasonómetro Achilles Express en comparación con el absorciómetro central de energía dual por rayos-x (cDXA) y evaluar su utilidad como dispositivo para la detección de la densidad ósea en la farmacia comunitaria.

MÉTODOs: Se llevó a cabo un estudio prospectivo en una farmacia comunitaria y clínica de pacientes ambulatorios en el que participaron mujeres de raza caucásica entre las edades de 25 a 35 años (jóvenes, saludables, grupo 1) y mujeres de raza caucásica de 45 años en adelante (en la posmenopausia, grupo 2). Se evaluó la DMO mediante cDXA de la muñeca no dominante, la cadera, y la vértebra. Se evaluó la DMO mediante CUS del talón, utilizando el dispositivo Achilles Express. Las mediciones principales de los resultados fueron la correlación de las puntuaciones $t$ entre el cDXA y las mediciones del CUS utilizando la prueba de correlación de Pearson.

RESULTADOS: Se inscribieron 22 (30 \pm 4 años) y 31 (55 \pm 17 años) mujeres en 2 grupos, respectivamente. Se encontraron correlaciones significativas entre el CUS y las puntuaciones $t$ mediante cDXA en la cadera y la vértebra en ambos grupos. Los coeficientes de la correlación para el CUS en comparación con el cDXA de la cadera fueron 0.51 (95\% CI 0.11 a 0.77 ) y 0.70 (95\% CI 0.46 a 0.85$)$ en los grupos 1 y 2 , respectivamente. Los coeficientes de la correlación para el CUS en comparación con el cDXA de la vértebra fueron 0.64 (95\% CI 0.31 a 0.84) y 0.60 (9\%5 CI 0.31 a 0.79 ) en los grupos 1 y 2 , respectivamente. El dispositivo CUS tiene una sensibilidad de $88 \%$ y una especificidad de $71 \%$ para detectar una puntuación $t$ mediante cDXA en la cadera menor de -1 .

CONCLUSIONES: El ultrasonómetro Achilles Express es una herramienta razonable para detectar una DMO baja en mujeres en la posmenopausia.

\section{Rafaela Mena}

\section{RÉSUMÉ}

INTRODUCTION: Les appareils à ultrasons quantitatifs (USQ) sont mobiles, facile à faire fonctionner, et représentent une option peu coûteuse pour le dépistage de l'ostéoporose au point d'intervention. Les pharmaciens en pratique communautaire devraient connaître la précision, la sensibilité, et la spécificité de ces appareils avant leur achat. OBJECTIF: Déterminer la précision, la sensibilité, et la spécificité de l'appareil Achilles Express, comparer ces paramètres à ceux de l'absorptiométrie biénergique à rayons $\mathrm{X}(\mathrm{ABX})$, et déterminer l'utilité de l'appareil pour le dépistage de l'ostéoporose en pharmacie communautaire.

DEVIS EXPÉRIMENTAL: Une étude prospective a été conduite chez un groupe de femmes âgées de 25 à 35 ans (groupe témoin) et un groupe de femmes âgées de 45 ans et plus (groupe de femmes ménopausées) identifiées à partir d'une pharmacie communautaire et d'une clinique de consultations externes. La densité minérale osseuse a été mesurée par $\mathrm{ABX}$ au niveau du poignet non dominant, de la hanche, et de la colonne vertébrale alors que les mesures avec l'USQ se sont faites au niveau du talon en utilisant l'appareil Achilles Express. Les résultats des 2 appareils ont été comparés par le coefficient de corrélation de Pearson. RÉSULTATS: Vingt-deux femmes ( $30 \pm 4$ ans) ont été inclues dans le groupe témoin et $31(55 \pm 17$ ans) dans le groupe de femmes ménopausées. Des corrélations significatives ont été observées entre l'USQ et la mesure par ABX de la hanche et de la colonne vertébrale. Les coefficients de corrélations pour la hanche étaient de 0.51 (95\% IC 0.11 à 0.77 ) pour le groupe témoin et de 0.70 (95\% IC 0.46 à 0.85 ) pour le groupe de femmes ménopausées. Les coefficients de corrélation pour la colonne vertébrale étaient de 0.64 (95\% IC 0.31 à 0.84 ) pour le groupe témoin et de 0.60 ( $95 \%$ IC 0.31 à 0.79 ) pour le groupe de femmes ménopausées. La sensibilité de l'appareil USQ à détecter un score de moins de 1 à la hanche était de $88 \%$ alors que sa spécificité était de $71 \%$. ConcLusions: L'appareil Achilles Express est d'une efficacité raisonnable pour le dépistage de l'ostéoporose chez les femmes ménopausées. 